This is the last draft sent to the Editorial by the authors of the article:

M. GÓMEZ, S. F. MEDINA
"Recrystallisation driving and pinning forces during hot rolling of a low
Nb-microalloyed steel"
Materials Science Forum
Vol. $500-501$ (2005), Pages: 147-154
DOI: $10.4028 / w w w . s c i e n t i f i c . n e t / M S F .500-501.147$
ISSN: $0255-5476$

To be published in Digital.CSIC, the Institutional Repository of the Spanish National Research Council (CSIC)

See more papers from the authors on:

$\underline{\text { http://digital.csic.es }}$

http://www.researcherid.com/rid/B-7922-2008 


\title{
Recrystallisation Driving and Pinning Forces during Hot Rolling of a Low Nb-Microalloyed Steel
}

\author{
M. Gómez ${ }^{1, a}$ and S. F. Medina ${ }^{1, b}$ \\ ${ }^{1}$ National Center for Metallurgical Research (CENIM-CSIC), Av. Gregorio del Amo 8, 28040-Madrid, \\ Spain \\ amgomez@cenim.csic.es, bsmedina@cenim.csic.es
}

Keywords: microalloyed steel, hot rolling, static recrystallisation, driving forces, pinning forces.

\begin{abstract}
The values of recrystallisation driving $\left(F_{\mathrm{R}}\right)$ and pinning forces $\left(F_{\mathrm{P}}\right)$ during hot rolling of a low Nb-microalloyed steel are calculated using several expressions found in the literature. A comparative study of the hypothesis about the interaction between precipitates and migrating grain boundaries is carried out, and the methods for estimation of volume fraction of precipitates and dislocation density are assessed. Though the criterion selected greatly influences the values obtained for both forces, it is always found that $F_{\mathrm{P}}$ grows faster than $F_{\mathrm{R}}$ as rolling temperature drops.
\end{abstract}

\section{Introduction}

The effect of solutes in microalloyed steels is not negligible, but the main reason of the presence of microalloying elements in these steels is the interaction of precipitates of these elements with migrating austenite grain boundaries. Precipitates cause a decrease in the effective grain boundary area and therefore in the associated surface energy, and this obstruction of grain boundary motion or pinning effect of precipitates is much stronger than solute drag.

In 1948, Zener [1] proposed that the driving pressure for grain growth due to the curvature of the boundary would be counteracted in particle-containing materials by a pinning pressure exerted by the particles on the boundary. Normal grain growth would be completely inhibited when the grain size reached a maximum, given by the critical radius $R_{\mathrm{C}}=4 r / 3 f$ where $r$ is the radius of the pinning particles and $f$ their volume fraction. This important equation has served as starting point for lots of studies about normal and abnormal grain growth developed by several authors [2]. Most of these works have found similar equations.

Many authors [3-8] have assessed the relationship between grain size and precipitation state (size, distribution, volume fraction, stability). To control grain size at high temperatures, there should be many fine particles and solubility temperature $T_{\mathrm{s}}$ should be high enough, but it is also essential that particles do not coarsen or coalesce at temperatures below $T_{\mathrm{s}}[9]$.

One of the most interesting aspects of Zener equation is its application to other annealing phenomena occurring in particle-containing materials apart from grain growth, especially static recrystallisation of microalloyed steels. Many models about the inhibition of recrystallisation by precipitates of microalloying elements have been presented [10,11]. In summary, all these hypothesis start from the same idea, similar to Zener's one: there is a driving pressure (usually treated as "force") of recrystallisation $F_{\mathrm{R}}$ that comes from stored energy of deformation applied to steel, and an opposite pinning force $F_{\mathrm{P}}$ exerted by fine precipitates. Depending on the net driving pressure $\left(F_{\mathrm{R}}-F_{\mathrm{P}}\right)$, recrystallisation progresses or stops.

Although the problem seems quite simple to pose, its difficulty lies in the correct calculation of $F_{\mathrm{R}}$ and $F_{\mathrm{P}}$. Some factors influencing the values of these forces are parameters whose determination is not straightforward and that have to be estimated. The different criteria or hypothesis adopted will lead to considerable differences, even of some orders of magnitude.

Expressions for the Calculation of Driving Forces for Static Recrystallization. According to the model of strain induced grain boundary migration [12], recrystallisation driving force $F_{\mathrm{R}}$ comes 
from the difference on dislocation density across the moving grain boundary separating two adjacent grains. This force can be expressed as:

$$
F_{R}=\mu b^{2} \Delta \rho / 2 \text {. }
$$

where $\mu$ is the shear modulus ( $4 \cdot 10^{4} \mathrm{MN} / \mathrm{m}^{2}$ for austenite), $b$ is the Burgers vector $\left(2 \cdot 10^{-10} \mathrm{~m}\right)$ and $\Delta \rho$ is the change in dislocation density. Due to the lack of direct and reliable measurements, the value of $\Delta \rho$ has to be estimated. To do that, most authors [11,13,14] use the Keh equation [15], which relates the increase in dislocation density during work hardening to the rise in flow stress $\Delta \sigma$ :

$$
\Delta \sigma=0,2 \mu b \sqrt{\Delta \rho}
$$

The value of $\Delta \sigma$ should be obtained from the subtraction of initial flow stress $\sigma_{0}$ to maximal or final flow stress $\sigma$ reached in the $\sigma-\varepsilon$ curve, as done by Dutta et al. [16]:

$$
\Delta \sigma=\sigma-\sigma_{0}=M \alpha \mu b \sqrt{\Delta \rho}
$$

where $M$ is Taylor factor and $\alpha$ is a constant taken to be 0.15 . However, it is very common to equalize $\Delta \sigma$ and maximal $\sigma$ [17]. Palmiere et al. [14] affirm that stress obtained from mechanical testing only represents an average flow stress and recommend to consider the flow stress at the grain boundaries, which is approximately 1.5 times the average flow stress. In a previous work these authors measure a potential driving force by calculating the area under the flow curve [18].

Despite Eq. 2 is very often used, it must be taken into account that Keh's work deals with $\alpha$-iron and $\Delta \sigma-\Delta \rho$ relationship should be something different when studying austenite. Eq. 3 [16] is more general and can be applied to $\gamma$-iron by using $M=3.1$. However, these authors need to introduce a "fitting factor" [19] to adjust the dislocation density, what shows again the difficulty of having an accurate estimation of $\Delta \rho$ from $\Delta \sigma$ values. Eq. 3 is almost equivalent to that used by Sun et al. [17] where $\alpha=1 / 2 \pi=0,159 \approx 0,15$.

Expressions for the Calculation of Pinning Forces for Static Recrystallization. According to Zener postulates [1], pinning force $F_{\mathrm{P}}$ arises from the area of boundary blanked of by precipitates. For a population of $N_{\mathrm{s}}$ particles per unit area of grain boundary having a mean radius $r, F_{\mathrm{P}}$ will be:

$$
F_{p}=\pi r \gamma N_{s} .
$$

where $\gamma$ is the interfacial energy per unit area of boundary $\left(0.8 \mathrm{~J} / \mathrm{m}^{2}\right.$ in austenite). This equation has been later modified by Gladman [5]:

$$
F_{p}=4 r \gamma N_{s}
$$

Knowing that number of particles per unit volume $N_{\mathrm{v}}$ and volume fraction $f$ obey:

$$
N_{v}=\frac{3 f}{4 \pi r^{3}}
$$

three different models to calculate $F_{\mathrm{P}}$ have been proposed, depending on the $N_{\mathrm{s}}-N_{\mathrm{v}}$ relationship:

(a) Rigid boundary model (RBM). A rigid boundary interacts with only those particles of random distribution with centers that lie within $\pm r$ of the boundary plane.

(b) Flexible boundary model (FBM) [11]. An infinitely flexible boundary interacts with every 
particle in the 3-D array until it is fully pinned. It leads to much higher values of $F_{\mathrm{P}}$.

(c) Sub-boundary model (SBM) [10]. Particles lie on sub-boundaries in the hot-worked structure. Values of $F_{\mathrm{P}}$ predicted are higher than previous ones.

Basic interpretation of the three models is the same: the finer and more abundant the precipitates are, the stronger the pinning force $F_{\mathrm{p}}$ results. The formulae for the models are:

$$
\begin{aligned}
& F_{p}=\frac{6 \gamma f}{\pi r} . \\
& F_{p}=\frac{3 \gamma f^{2 / 3}}{\pi r} . \\
& F_{p}=\frac{3 \gamma f l}{2 \pi r^{2}} .
\end{aligned}
$$

$l$ is the average subgrain diameter, which varies from 0.47 to $0.97 \mu \mathrm{m}[10,11,20]$.

Volume fraction of precipitates $f$ can be determined by thermodynamical calculations, establishing a mass balance under equilibrium conditions where the quantity of elements (microalloying, interstitials) precipitated at every temperature is predicted by solubility product. The work of Manohar et al. [21] for titanium nitride can be extended to other nitrides of microalloying elements or other compounds (carbides, carbonitrides). To carry out these calculations, the following data are needed: the stoechiometric ratio of the atomic weights of elements in precipitated compound, the solubility product [23], the Avogadro's number, the volume of unit cell of materials (compound and austenite), the number of atoms per unit cell and the atomic weights.

Volume fraction of precipitates can also be estimated in a completely different way, from data extracted in observation of samples or replicas by means of transmission electron microscopy (TEM). These data are the mean value of precipitate diameters (mean particle size $d$ ), standard deviation of size distribution $(\sigma)$ and precipitate number density per unit area $\left(N_{\mathrm{p}}\right)$. These three values allow the calculation of $f$ thanks to the expression presented by Ashby and Ebeling [22] to transform surface measurements into volume variables:

$$
f=\frac{\pi}{6} N_{p}\left(d^{2}+\sigma^{2}\right)
$$

Making use of Eqs. 1 to 10 and the aforesaid hypothesis, present study tries to carry out a global comparison of methods and criteria of estimation of driving and pinning forces, particularly under continuous cooling conditions similar to those of hot rolling of steel.

\section{Experimental Procedure}

The steel studied, whose composition is shown in Table 1, was manufactured by Electroslag Remelting (ESR). Rolling simulations tests were carried out in a computer-controlled hot torsion machine, on specimens with a gauge length of $50 \mathrm{~mm}$ and a diameter of $6 \mathrm{~mm}$. Prior to the simulation tests the specimens were austenitised at $1250^{\circ} \mathrm{C}$ for $10 \mathrm{~min}$. This reheating conditions were enough to completely dissolve the niobium precipitates, as solubility temperatures calculated for carbonitrides, nitrides and carbides were equal to $1037{ }^{\circ} \mathrm{C}, 965^{\circ} \mathrm{C}$ and $986^{\circ} \mathrm{C}$, respectively [23]. The temperature was then lowered to that corresponding to the first pass, which was $1150^{\circ} \mathrm{C}$. The simulations consisted of the performance of 20 passes, with a temperature step of $25^{\circ} \mathrm{C}$ between passes, the last pass being carried out at $675^{\circ} \mathrm{C}$. The strain applied in each pass was of 0.35 and the strain rate was 
equal to $3.63 \mathrm{~s}^{-1}$. Two different interpass times $(\Delta \mathrm{t})$ of 20 and $200 \mathrm{~s}$ were used.

Table 1. Chemical composition of steel studied [mass \%].

\begin{tabular}{|c|c|c|c|c|c|c|c|c|}
\hline $\mathrm{C}$ & $\mathrm{Si}$ & $\mathrm{Mn}$ & $\mathrm{P}$ & $\mathrm{S}$ & $\mathrm{Al}$ & $\mathrm{Nb}$ & $\mathrm{N}$ & $\mathrm{O}$ \\
\hline 0.20 & 0.20 & 1.0 & 0.024 & 0.013 & 0.006 & 0.007 & 0.0056 & 0.0057 \\
\hline
\end{tabular}

To study the influence of interpass time on several aspects (microstructure, precipitation state, pinning forces), four samples were water-quenched from the same temperatures $\left(900{ }^{\circ} \mathrm{C}\right.$ and $775{ }^{\circ} \mathrm{C}$ ) along the two hot rolling simulation schedules planned. In every sample a last deformation step was performed and temperature was then lowered $25{ }^{\circ} \mathrm{C}$ for the corresponding interpass time to reach the quench temperature. Microstructures were observed on a longitudinal surface and the characteristics of precipitates were determined by TEM, using the carbon extraction replica technique.

\section{Results and Discussion}

Hot Rolling Simulations. Critical Temperatures and Accumulated Stress. The torsion test gives the values of torque applied versus the number of turns made on the specimen, which are transformed respectively into equivalent stress and strain using Von Mises criterion [24]. After applying the method of Jonas et al. [25], Mean Flow Stress (MFS) can be represented versus the inverse of absolute temperature to obtain plots such as Fig. 1a, which shows this graphic representation for an interpass time of $20 \mathrm{~s}$. In this figure four zones can be successively distinguished: complete recrystallisation of austenite between passes at highest temperatures (I), inhibition of recrystallisation and strengthening of austenite (II), austenite $\rightarrow$ ferrite partial transformation (III) and finish of ferrite formation followed by eutectoid transformation (IV).

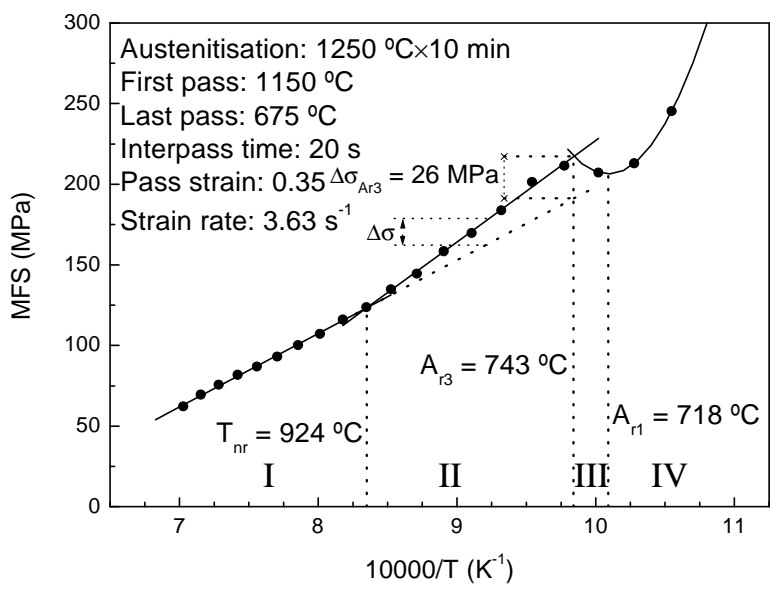

a)

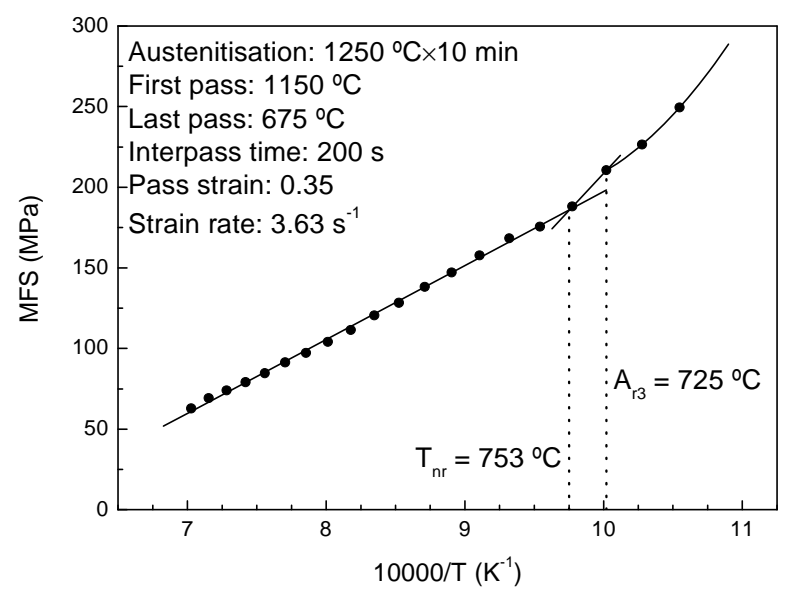

b)

Figure 1. Mean Flow Stress (MFS) versus the inverse of temperature, according to given schedules. a) $\Delta \mathrm{t}=20 \mathrm{~s}$. Determination of critical temperatures and accumulated stress $(\Delta \sigma)$. b) $\Delta \mathrm{t}=200 \mathrm{~s}$.

The intersection of the straight regression lines of phases I and II defines the value of $T_{\mathrm{nr}}$ and the intersection of the regression lines of phases II and III determines the value of $A_{\mathrm{r} 3}$. The value of $A_{\mathrm{r} 1}$ is placed at a point close to the minimum of the parabola corresponding to phases III and IV [25]. In this way, the values found for the three critical temperatures when interpass time was $20 \mathrm{~s}$ were: $T_{\mathrm{nr}}=924$ ${ }^{\circ} \mathrm{C}, A_{\mathrm{r} 3}=743{ }^{\circ} \mathrm{C}, A_{\mathrm{r} 1}=718{ }^{\circ} \mathrm{C}$. When deformed at temperatures below $T_{\mathrm{nr}}$, austenite accumulates a stress $\Delta \sigma$ due to incomplete recrystallisation. The value of accumulated stress $\Delta \sigma$ can be measured from the graph of MFS versus 1/T and will be given by the length of the vertical segment limited by the phase I and phase II regression lines [26] as is illustrated in Fig. 1a. When T $=A_{\mathrm{r} 3}, \Delta \sigma$ reaches its maximum value, which in this case is equal to $26 \mathrm{MPa}$. 
Fig. 1b shows the graphic representation of MFS versus $1 / \mathrm{T}$ for an interpass time of $200 \mathrm{~s}$. In this case, the longer time between passes leads to a much lower value of $T_{\mathrm{nr}}\left(753^{\circ} \mathrm{C}\right)$, very near $A_{\mathrm{r} 3}(725$ ${ }^{\circ} \mathrm{C}$ ). Maximal accumulated stress is also lower than that obtained when interpass time is $20 \mathrm{~s}$. This small value of $\Delta \sigma$ makes it impossible to distinguish a descent in MFS value and to determine $A_{\mathrm{r} 1}$.

Microstructure and Precipitation State. In previous studies [27] the evolution of austenite microstructure and precipitation state during hot rolling and the influence of interpass time on these evolutions were studied. It has been found that reduction of interpass time is crucial to obtain a hardened austenite at the end of rolling, i.e. to reach a near to pancake structure prior to phase transformation. It was also concluded that accumulated stress $\Delta \sigma$ is an adequate estimation of austenite strengthening between $T_{\mathrm{nr}}$ and $A_{\mathrm{r} 3}$.

Studies of precipitation state were carried out by TEM on replicas of quenched samples. A large population of particles of niobium carbonitride was counted and measured. Mean size, standard deviation and particle density were calculated (Table 2) and it was found that evolution of size of precipitates during hot rolling of this low Nb-microalloyed steel noticeably depends on interpass time $\Delta \mathrm{t}$. When $\Delta \mathrm{t}$ is $20 \mathrm{~s}$, particle size keeps roughly constant $(\approx 18 \mathrm{~nm})$, but a longer time of $200 \mathrm{~s}$ allows precipitates to coarsen at higher temperatures. In this second case, the decrease in diffusivity and the increase in the number of available sites for the nucleation of precipitates due to hardening of steel provoked by continuous cooling $[16,19]$ counteract coalescence and lead to a drop in mean particle size as hot rolling process progresses (from $54 \mathrm{~nm}$ at $900{ }^{\circ} \mathrm{C}$ to $16 \mathrm{~nm}$ at $775^{\circ} \mathrm{C}$ ) [27].

Table 2. Results of study of precipitation state by transmission electron microscopy (TEM). Hot rolling simulations by multipass torsion followed by quenching. Mean particles size $(d)$, standard deviation $(\sigma)$ and number of particles per unit area of replica $\left(N_{\mathrm{p}}\right)$.

\begin{tabular}{|c|c|c|c|c|c|c|}
\hline \multirow{2}{*}{$\begin{array}{c}\Delta \mathrm{t} \\
{[\mathrm{s}]}\end{array}$} & $\begin{array}{c}\text { Number of } \\
\text { passes }\end{array}$ & \multicolumn{2}{|c|}{ Temperature $\left[{ }^{\circ} \mathrm{C}\right]$} & \multicolumn{3}{|c|}{ TEM Data } \\
\cline { 2 - 7 } & Last pass & Quench & $d[\mathrm{~nm}]$ & $\sigma[\mathrm{nm}]$ & $N_{\mathrm{p}}\left[\cdot 10^{13} \mathrm{~m}^{-2}\right]$ \\
\hline \multirow{2}{*}{20} & 10 & 925 & 900 & 19 & 17 & 3.5 \\
\cline { 2 - 7 } & 15 & 800 & 775 & 17 & 22 & 9.8 \\
\hline \multirow{2}{*}{200} & 10 & 925 & 900 & 54 & 62 & 0.9 \\
\cline { 2 - 7 } & 15 & 800 & 775 & 16 & 21 & 17.7 \\
\hline
\end{tabular}

Determination of Driving and Pinning Forces for Recrystallization during Hot Rolling. Table 3 shows the mass percentages of niobium, nitrogen and carbon in solution and precipitated at quenching temperatures of samples studied by TEM, supposing a mass balance in equilibrium and precipitation of $\mathrm{NbC}_{0,7} \mathrm{~N}_{0,2}[21,23]$.

Table 3. Mass \% of Nb, N, C in solution and precipitated at quenching temperatures of samples studied by TEM, supposing the precipitation of $\mathrm{NbC}_{0,7} \mathrm{~N}_{0,2}[21,23]$.

\begin{tabular}{|c|c|c|c|c|c|c|}
\hline Temp. $\left[{ }^{\circ} \mathrm{C}\right]$ & $M_{\mathrm{s}}$ & $M_{\mathrm{p}}$ & $N_{\mathrm{s}}$ & $N_{\mathrm{p}}$ & $C_{\mathrm{s}}$ & $C_{\mathrm{p}}$ \\
\hline 900 & 0.0060 & 0.0010 & 0.0005 & 0.1995 & 0.0002 & 0.0054 \\
\hline 775 & 0.0069 & 0.0001 & 0.0006 & 0.1994 & 0.0002 & 0.0054 \\
\hline
\end{tabular}

Values of applied stress in $\sigma-\varepsilon$ curve corresponding to the pass of torsion test just before quenching allow calculation of driving forces $F_{\mathrm{R}}$ by means of Eqs. 1 to 3. Application of Eqs. 4 to 10 on data shown in Tables 2 and 3 let to know volume fraction $f$ and consequently the values of pinning forces $F_{\mathrm{P}}$ obtained from the different methods and hypothesis. Tables 4 and 5 respectively show the different values of $F_{\mathrm{R}}$ and $F_{\mathrm{P}}$ obtained at $900{ }^{\circ} \mathrm{C}$ and $775^{\circ} \mathrm{C}$. Depending on the method of estimation applied and the initial criteria or hypothesis proposed, considerable variations in $F_{\mathrm{R}}$ and especially in $F_{\mathrm{P}}$ values can be observed. Nevertheless, as rolling temperature drops, an increase in the value of both forces is observed in all cases, $F_{\mathrm{P}}$ growing faster than $F_{\mathrm{R}}$. During hot rolling, steels is under 
continuous cooling and population of microalloying particles capable to impede the grain boundary motion increases, so completion of static recrystallisation of austenite during interpass time is more and more difficult and a $T_{\mathrm{nr}}$ can appear (as occurs in both simulations).

Table 4. Estimation of recrystallisation driving force $\left(F_{\mathrm{R}}\right)$ at several temperatures. Comparison of results of different equations relating dislocation density $(\Delta \rho)$ and rise in stress during deformation

$(\Delta \sigma)$ and influence of criteria to define $\Delta \sigma$.

\begin{tabular}{|c|c|c|c|c|c|c|c|c|}
\hline \multicolumn{6}{|c|}{ Relation $\Delta \sigma-\Delta \rho \rightarrow$} & \multicolumn{6}{|c|}{$\Delta \sigma=0.2 \mu b \sqrt{\Delta \rho}$} & $\Delta \sigma=M \alpha \mu b \sqrt{\Delta \rho}$ \\
\hline \multicolumn{2}{|c|}{ Criterion for $\Delta \sigma \rightarrow$} & \multicolumn{2}{|c|}{$\Delta \sigma=\sigma$ max. } & \multicolumn{2}{c|}{$\Delta \sigma=1.5 \cdot \sigma$ max. } & \multicolumn{2}{c|}{$\Delta \sigma=$ MFS } & $\begin{array}{c}\Delta \sigma=\sigma \text { max. } \\
M=3.1 ; \alpha=0.15\end{array}$ \\
\hline \multirow{2}{*}{$\begin{array}{c}\Delta \mathrm{t} \\
{[\mathrm{s}]}\end{array}$} & $\begin{array}{c}\text { Last pass } \\
\text { temp. }\left[{ }^{\circ} \mathrm{C}\right]\end{array}$ & $\begin{array}{c}\Delta \sigma \\
{[\mathrm{MPa}]}\end{array}$ & $\begin{array}{c}F_{\mathrm{R}} \\
{\left[\mathrm{MN} / \mathrm{m}^{2}\right]}\end{array}$ & $\begin{array}{c}\Delta \sigma \\
{[\mathrm{MPa}]}\end{array}$ & $\begin{array}{c}F_{\mathrm{R}} \\
{\left[\mathrm{MN} / \mathrm{m}^{2}\right]}\end{array}$ & $\begin{array}{c}\Delta \sigma \\
{[\mathrm{MPa}]}\end{array}$ & $\begin{array}{c}F_{\mathrm{R}} \\
{[\mathrm{MN} / \mathrm{m}]}\end{array}$ & $\begin{array}{c}F_{\mathrm{R}} \\
{\left[\mathrm{MN} / \mathrm{m}^{2}\right]}\end{array}$ \\
\hline \multirow{2}{*}{20} & 925 & 162 & 8.20 & 243 & 18.45 & 124 & 4.78 & 1.52 \\
\cline { 2 - 10 } & 800 & 223 & 15.54 & 334 & 34.96 & 184 & 10.56 & 2.87 \\
\hline \multirow{2}{*}{200} & 925 & 160 & 7.99 & 240 & 17.99 & 120 & 4.53 & 1.48 \\
\cline { 2 - 9 } & 800 & 215 & 14.46 & 323 & 32.53 & 168 & 8.84 & 2.67 \\
\hline
\end{tabular}

Table 5. Estimation of recrystallisation pinning force $\left(F_{\mathrm{P}}\right)$ at several temperatures. Comparison of results of the models of interaction between particles and grain boundaries and influence of the methods to estimate precipitated volume fraction $f$. Average subgrain diameter $l=0.5 \mu \mathrm{m}$

\begin{tabular}{|c|c|c|c|c|c|}
\hline \multirow[b]{2}{*}{$\begin{array}{l}\Delta \mathrm{t} \\
{[\mathrm{s}]}\end{array}$} & \multirow{2}{*}{$\begin{array}{c}\text { Quench } \\
\text { Temp. } \\
{\left[{ }^{\circ} \mathrm{C}\right]}\end{array}$} & $f \cdot 10^{-4}$ & \multicolumn{3}{|c|}{$F_{p}=4 r \gamma N_{s}\left[\mathrm{MN} / \mathrm{m}^{2}\right]$} \\
\hline & & Equil & RBM: $\frac{6 \gamma f}{\pi r}$ & FBM: $\frac{3 \gamma f^{2 / 3}}{\pi r}$ & SBM: $\frac{3 \gamma f l}{2 \pi r^{2}}$ \\
\hline \multirow{2}{*}{20} & 900 & 0.65 & 0.0106 & 0.1317 & 0.1415 \\
\hline & 775 & 0.74 & 0.0132 & 0.1564 & 0.1903 \\
\hline \multirow{2}{*}{200} & 900 & 0.65 & 0.0036 & 0.0455 & 0.0169 \\
\hline & 775 & 0.74 & 0.0140 & 0.1660 & 0.2144 \\
\hline
\end{tabular}

Some methods or criteria leading to unsatisfactory values of $F_{\mathrm{R}}$ and $F_{\mathrm{P}}$ can be rejected. $T_{\mathrm{nr}}$ temperature marks the beginning of recrystallisation inhibition among successive rolling passes. If it is supposed that this blocking effect occurs when $F_{\mathrm{R}} \approx F_{\mathrm{P}}$, both forces should not be extremely different on cases studied. Volume fraction $f$ calculated by thermodynamical methods (mass balance) is much lower than that estimated by Eq. 10 and pinning forces calculated with this $f$ do not reach values of the same order of magnitude than those of driving forces. Therefore, it seems that -when aiming to estimate $F_{\mathrm{P}}$ with known equations- method of Ashby is more adequate to calculate $f$ than thermodynamic calculations. Certainly, the first method is more frequently used $[10,13,14,18,20]$ than the second [11].

Some authors $[10,11]$ affirm that SBM is the most realistic and accurate model, as predicted $F_{\mathrm{P}}$ is rather higher than that obtained with the other models (RBM, FBM) and it is usually of the same order as $F_{\mathrm{R}}$ in cases where recrystallisation inhibition is observed. For this reason, SBM is quite often applied $[14,18,20]$. However, in present case (and taking into account data from TEM) SBM offers too high values of $F_{\mathrm{P}}$ when compared to $F_{\mathrm{R}}$, despite having considered a low value of $l(0.5 \mu \mathrm{m})$. In conclusion, FBM and RBM appear in this study as more adequate hypothesis than SBM.

On the other hand, it seems that the most adequate way to estimate dislocation density for 
calculation of $F_{\mathrm{R}}$ is to use Eq. 2 with the criterion of $\Delta \sigma=$ maximal stress or MFS (area under the curve divided by strain applied), as the other methods lead to higher differences between $F_{\mathrm{R}}$ and $F_{\mathrm{P}}$.

Fig. 2 shows the evolution of $F_{\mathrm{R}}$ and $F_{\mathrm{P}}$ versus rolling temperature. Fig. 2a has been plotted with the average of all values found for $F_{\mathrm{R}}$ and $F_{\mathrm{P}}$, while Fig. $2 \mathrm{~b}$ shows a particular case where $F_{\mathrm{R}}$ and $F_{\mathrm{P}}$ reach very similar values: calculation of $F_{\mathrm{R}}$ using Eq. 2 with $\Delta \sigma=$ MFS, and estimation of $F_{\mathrm{P}}$ by FBM criterion using TEM data to approximate $f$. In both figures the evolution of $F_{\mathrm{R}}$ versus temperature is similar: at higher temperatures $\left(900{ }^{\circ} \mathrm{C}\right)$, applied stress is almost equal for both interpass times and driving forces $F_{\mathrm{R}}$ are analogous, but at $\mathrm{T}=775^{\circ} \mathrm{C} F_{\mathrm{R}}$ is something higher when $\Delta \mathrm{t}=20 \mathrm{~s}$, as austenite accumulates a strengthening due to recrystallisation inhibition below $T_{\mathrm{nr}}$ and increase in dislocation density $\Delta \rho$ is higher.

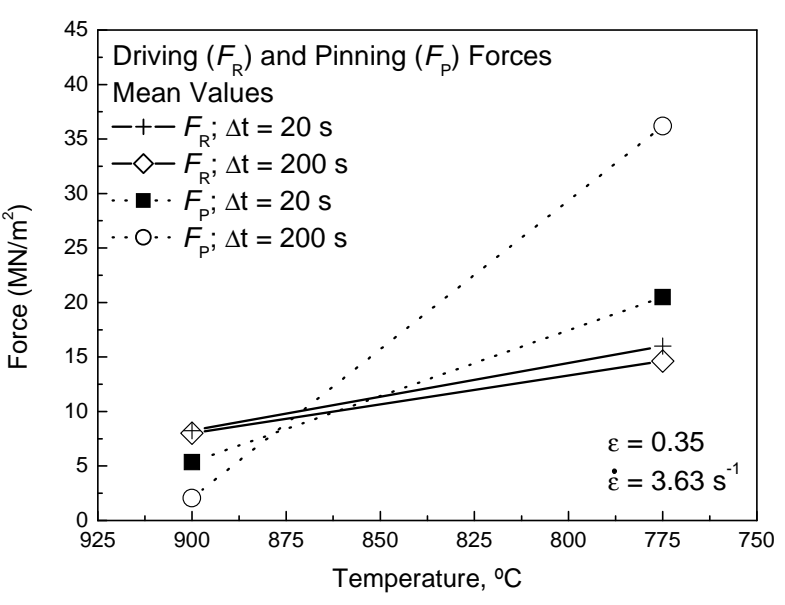

a)

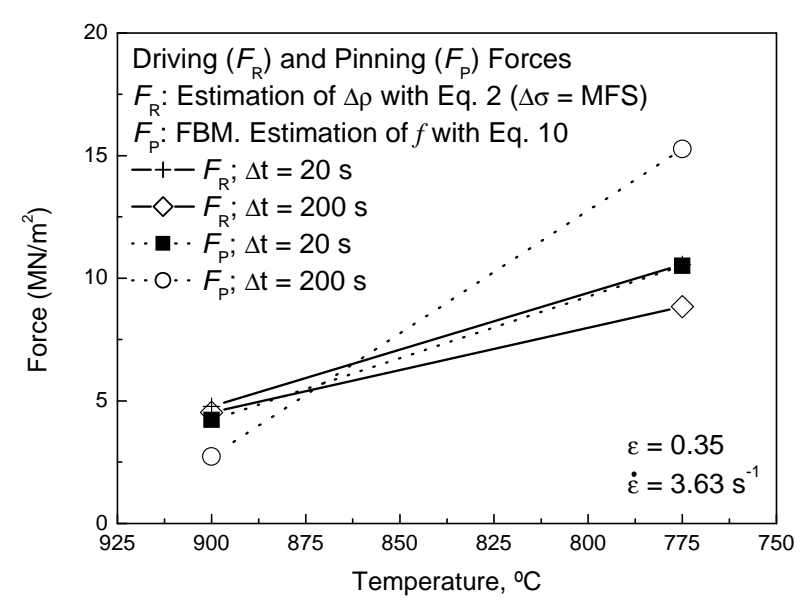

b)

Figure 2. Estimation of recrystallisation driving $\left(F_{\mathrm{R}}\right)$ and pinning forces $\left(F_{\mathrm{P}}\right)$ at $900{ }^{\circ} \mathrm{C}$ and $775{ }^{\circ} \mathrm{C}$ for the two hot rolling schedules studied ( $\Delta \mathrm{t}=20 \mathrm{~s}$ and $200 \mathrm{~s})$. a) Mean values of calculated $F_{\mathrm{R}}$ and $F_{\mathrm{P}}$. b) $F_{\mathrm{R}}$ calculated after estimation of dislocation density with Eq. 2 assuming $\Delta \sigma=$ MFS and $F_{\mathrm{P}}$ calculated following FBM criterion and using TEM data to estimate precipitated volume fraction $f$.

Pinning force $F_{\mathrm{P}}$ at $900{ }^{\circ} \mathrm{C}$ is lower for the longest interpass time ( $\Delta \mathrm{t}=200 \mathrm{~s}$ ) because this time allows a considerable particle coarsening compared to $\Delta \mathrm{t}=20 \mathrm{~s}$. For this reason, recrystallisation is complete $\left(T_{\mathrm{nr}}=753^{\circ} \mathrm{C}\right.$ for $\left.\Delta \mathrm{t}=200 \mathrm{~s}\right)$ and recrystallised grain growth can even appear [27], while for $\Delta \mathrm{t}=20 \mathrm{~s}$ inhibition of recrystallisation has already started $\left(T_{\mathrm{nr}}=924{ }^{\circ} \mathrm{C}\right)$. However, $F_{\mathrm{P}}$ grows much faster versus temperature drop for the longest $\Delta \mathrm{t}$, probably due to a massive precipitation of fine particles, in such a way that, at $\mathrm{T}=775^{\circ} \mathrm{C}, F_{\mathrm{P}}$ value for $\Delta \mathrm{t}=200 \mathrm{~s}$ is considerably higher than $F_{\mathrm{P}}$ for $\Delta \mathrm{t}$ $=20 \mathrm{~s}$. The value of $T_{\mathrm{nr}}$ for $\Delta \mathrm{t}=200 \mathrm{~s}$ is $753^{\circ} \mathrm{C}$, but $F_{\mathrm{P}}$ at $775{ }^{\circ} \mathrm{C}$ is much higher than $F_{\mathrm{R}}$. This result shows the difficulty of establishing a definite relationship between $T_{\mathrm{nr}}$ value and the balance $\left(F_{\mathrm{R}}-F_{\mathrm{P}}\right)$ and the convenience of carrying out more complete studies to explain this aspect.

\section{Conclusions}

1) During rolling, pinning $\left(F_{P}\right)$ and driving forces $\left(F_{R}\right)$ increase as temperature drops, but $F_{P}$ grows faster than $F_{\mathrm{R}}$ and so recrystallisation inhibition appears at temperatures below $T_{\mathrm{nr}}$.

2) There are many hypothesis and variables influencing the value of $F_{R}$ and $F_{P}$ and variations in their values are very large, especially for $F_{\mathrm{P}}$.

3) To calculate $F_{R}$, it is advisable to estimate the increase in dislocation density $\Delta \rho$ with Keh equation (Eq. 2), equating flow stress $\Delta \sigma$ to the maximal stress or the Mean Flow Stress.

4) When calculating $F_{\mathrm{P}}$, estimation of precipitated volume fraction $f$ from TEM data is more suitable than thermodynamical calculations, as the latter lead to extremely low values of $F_{\mathrm{P}}$.

5) In this study, the sub-boundary model offers too high values of $F_{P}$ and flexible boundary 
model (FBM) seems more appropriate.

\section{Acknowledgements}

The authors thank I3P Program (CSIC/European Social Fund) for funding the grant of Dr. Gómez.

\section{References}

[1] C.S. Smith: Trans. AIME, 175, 15, (1948), p. 15. (Ref. 24).

[2] P.A. Manohar, M. Ferry and T. Chandra: ISIJ Int., Vol. 38, 9, (1998), p. 913.

[3] M. Hillert: Acta Metal. 13, (1965), p. 227

[4] V. Randle and B. Ralph: Acta Metal., 35, 5, (1986), p. 891.

[5] T. Gladman: Proc. Royal Society, 294 (1966), p. 298.

[6] T. Gladman and F.B. Pickering: JISI; 205, 6 (1967), p. 653.

[7] T. Gladman: Mater. Sci. Forum, 94-96 (1992), p. 113.

[8] P. R. Rios: Acta Metall. 35, 12 (1987), p. 2805.

[9] H. Adrian and F.B. Pickering: Mater. Sci. and Technol., 7, 2 (1991), p. 176.

[10] S.S Hansen, J.B. Van der Sande and M. Cohen: Metal. Trans. 11A, 3 (1980), p. 387.

[11]L.J. Cuddy: Thermomechanical Processing of Microalloyed Austenite (The Metallurgical Society of AIME, Pittsburgh, PA, 1982), p. 129.

[12]P.A. Beck and P.R. Sperry: Journal of Applied Physics, Vol. 25, (1950), p. 150.

[13] O. Kwon and A.J. DeArdo: Acta Metal., 39, 4 (1991), p. 529.

[14]E.J. Palmiere, C.I. Garcia and A.J. DeArdo: Metall. Mater. Trans. 27A, (1996), p. 951.

[15] A.S. Keh: Direct Observations of Imperfections in Crystals (J.B. Newkirk and J.H. Wernick, eds. Wiley-Interscience, New York, 1962), p. 213.

[16]B. Dutta, E. Valdes and C.M. Sellars: Acta Metall. Mater. Vol. 40 (1992), p. 65.

[17] W.P. Sun, M. Militzer and J.J. Jonas: Metall. Trans. 23A, (1992), p. 3013.

[18] E.J. Palmiere, C.I Garcia, and A.J. DeArdo: Processing, Microstructure and Properties of Microalloyed and Other Modern HSLA Steels (I.S.S. of AIME, Warrendale, PA, 1992), p. 113.

[19]B. Dutta, E.J. Palmiere and C.M. Sellars: Acta Mater. Vol. 49 (2001), p. 785.

[20]W.M. Rainforth, M.P. Black, R.L. Higginson et al.: Acta Mater. 50, (2002), p. 735.

[21]P.A. Manohar, D.P. Dunne, T. Chandra and C.R Killmore: ISIJ Int., Vol. 36, 2, (1996), p. 194.

[22] M.F. Ashby, R. Ebeling: Trans. AIME, Vol. 236, (1966), p. 1396.

[23] E.T. Turkdogan: Trans. ISS, 3, 5 (1989), p. 61.

[24]A. Faessel: Rev. Metall. CIT, 33, 4 (1976), p.875.

[25]F.H. Samuel, S. Yue, J.J. Jonas and B.A. Zbinden: ISIJ Int., Vol. 29, 10, (1989), p. 878.

[26] M. Gómez, O. Hernanz, S.F. Medina, P. Tarín: Steel Research, Vol. 73, 10, (2002), p. 446.

[27] M. Gómez, S.F. Medina and P. Valles: 2nd International Conference on Thermomechanical

Processing of Steels, TMP'2004. Liege, Belgium. (Stahl Eisen 2004). 